\title{
Commentar \\ zur \\ Pharmacopoea Germanica
}

mit verdeutschtem Texte.

\author{
Für Apotheker, Aerzte und Medicinal-Beamte \\ unter Mitwirkung von \\ Professor Dr. Hermann von Boeck \\ bearbeitet von
}

\section{Ludwig Andreas Buchner,}

Doctor der Philosophie und Medicin, ordentlichem Professor der Pharmacie an der k. Ludwig-Maximilians-Universität in München, ordentlichem Mitgliede der k. bayerischen Akademie der Wissenschaften etc. etc.

In zwei Bänden.

\author{
Zweiter Band, \\ enthaltend den Commentar der Pharmakopoe. \\ Mit in den Text eingedruckten Holzschnitten.
}

\section{Erster Theil.}
MÜNCHEN,
V e r l a g vo n R. O I d e n b o r: $r$. $1 \leqslant 78$


